\title{
Cross-kingdom inhibition of bacterial virulence and communication by probiotic yeast metabolites
}

Orit Malka', Dorin Kalson ${ }^{1}$, Karin Yaniv², Reut Shafir², Manikandan Rajendran', Oshrit Ben-David², Ariel Kushmaro ${ }^{2,3^{*}}$, Michael M. Meijler ${ }^{1,3^{*}}$ and Raz Jelinek ${ }^{1,4^{*}}$ (D)

\begin{abstract}
Background: Probiotic milk-fermented microorganism mixtures (e.g., yogurt, kefir) are perceived as contributing to human health, and possibly capable of protecting against bacterial infections. Co-existence of probiotic microorganisms are likely maintained via complex biomolecular mechanisms, secreted metabolites mediating cellcell communication, and other yet-unknown biochemical pathways. In particular, deciphering molecular mechanisms by which probiotic microorganisms inhibit proliferation of pathogenic bacteria would be highly important for understanding both the potential benefits of probiotic foods as well as maintenance of healthy gut microbiome.
\end{abstract}

Results: The microbiome of a unique milk-fermented microorganism mixture was determined, revealing a predominance of the fungus Kluyveromyces marxianus. We further identified a new fungus-secreted metabolitetryptophol acetate - which inhibits bacterial communication and virulence. We discovered that tryptophol acetate blocks quorum sensing (QS) of several Gram-negative bacteria, particularly Vibrio cholerae, a prominent gut pathogen. Notably, this is the first report of tryptophol acetate production by a yeast and role of the molecule as a signaling agent. Furthermore, mechanisms underscoring the anti-QS and anti-virulence activities of tryptophol acetate were elucidated, specifically down- or upregulation of distinct genes associated with $V$. cholerae QS and virulence pathways.

Conclusions: This study illuminates a yet-unrecognized mechanism for cross-kingdom inhibition of pathogenic bacteria cell-cell communication in a probiotic microorganism mixture. A newly identified fungus-secreted molecule-tryptophol acetate-was shown to disrupt quorum sensing pathways of the human gut pathogen $V$. cholerae. Cross-kingdom interference in quorum sensing may play important roles in enabling microorganism coexistence in multi-population environments, such as probiotic foods and the gut microbiome. This discovery may account for anti-virulence properties of the human microbiome and could aid elucidating health benefits of probiotic products against bacterially associated diseases.

Keywords: Microbiome, Quorum sensing, Vibrio cholerae, Biofilms, Probiotic microorganisms, Kluyveromyces marxianus, Tryptophol acetate

\footnotetext{
*Correspondence: arielkus@bgu.ac.il; meijler@bgu.ac.il; razj@bgu.ac.il

${ }^{2}$ Avram and Stella Goldstein-Goren Department of Biotechnology Engineering, Ben-Gurion University of the Negev, 84105 Be'er Sheva, Israel

'Department of Chemistry, Ben-Gurion University of the Negev, 84105 Be'er Sheva, Israel

Full list of author information is available at the end of the article
}

C C The Author(s). 2021 Open Access This article is licensed under a Creative Commons Attribution 4.0 International License, which permits use, sharing, adaptation, distribution and reproduction in any medium or format, as long as you give appropriate credit to the original author(s) and the source, provide a link to the Creative Commons licence, and indicate if changes were made. The images or other third party material in this article are included in the article's Creative Commons licence, unless indicated otherwise in a credit line to the material. If material is not included in the article's Creative Commons licence and your intended use is not permitted by statutory regulation or exceeds the permitted use, you will need to obtain permission directly from the copyright holder. To view a copy of this licence, visit http://creativecommons.org/licenses/by/4.0/ The Creative Commons Public Domain Dedication waiver (http://creativecommons.org/publicdomain/zero/1.0/) applies to the data made available in this article, unless otherwise stated in a credit line to the data. 


\section{Background}

Probiotic milk-fermented microorganism mixtures (e.g., kefir, yogurt) are perceived and recognized as contributing to human health, and possibly capable of protecting against bacterial infections [1-4]. Co-existence and symbiosis of probiotic microorganisms are likely maintained via complex biological pathways, microorganism-secreted metabolites mediating intercellular communication, and other yet-unknown biochemical mechanisms. In particular, the means by which probiotic microorganisms inhibit proliferation of pathogenic bacteria are largely unknown; deciphering such mechanisms would be a major step towards both elucidating possible therapeutic benefits of probiotic foods as well as understanding the role of the gut microbiome in maintenance of human health and combating bacterial diseases.

Quorum sensing (QS), mediated by specific cellsecreted autoinducers, is the primary means of bacterial communication $[5,6]$. QS plays major role in the synchronized production of virulence factors, such as toxins and proteases, by bacterial populations, and direct relationships between QS and pathogenesis have been demonstrated [7]. QS pathways specifically induce formation of bacterial biofilms, which confer resistance to antimicrobial molecules and drugs. Furthermore, population-wide coordination via QS is essential for some bacteria both to defend themselves and to effectively attack their hosts [8]. Interestingly, inter-species bacterially secreted QS compounds have been also identified $[9,10]$. Significant efforts have been directed in recent years towards development of anti-bacterial therapeutic strategies based upon identification of antagonists or agonists in QS cascades [11, 12]. Such strategies have attracted considerable interest, as they circumvent the emergence of bacterial resistance to antibiotic compounds, a major and growing challenge in anti-bacterial therapeutics [13].

A recent study has shown that molecules secreted by a probiotic Bacillus strain interfered with cell-cell communication of a pathogenic bacterial species, Staphylococcus aureus [14]. In particular, that work pointed to QS pathways of pathogenic bacteria as possible targets for the secreted molecules. Notably, there has been no report of cross-kingdom effects upon QS pathways in probiotic microorganism populations. In this study, we identified, for the first time, a compound secreted by probiotic yeast that blocks bacterial communication and inhibit virulence of pathogenic bacteria. Specifically, we show that tryptophol acetate, secreted by Kluyveromyces marxianus, modulates QS of several Gram-negative bacterial pathogens. Although tryptophol acetate has been previously found in plants and algae $[15,16]$, this is the first report of its production by a yeast and particularly its role as a signaling molecule. The intriguing crosskingdom communication interference we identified may be a fundamental tenet of microorganism co-existence in complex multi-population environments (such as probiotic foods and the human gut microbiome) and may contribute to development of new therapeutic strategies.

\section{Results and discussion}

\section{Kefir composition}

In this work, we focused on milk-fermented Tibetan kefir as the source of secreted molecules interfering with bacterial communication. The microorganism populations of the kefir, outlined according to taxonomy annotation, were determined by total DNA shotgun sequencing and are depicted in Fig. 1a. The dominant genetic constituent of the kefir-approximately $70 \%$ of total reads-was Kluyveromyces marxianus, 24\% were Lactobacillus species, and the remainder comprised of other genera, including Propionibacterium, Lactococcus lactis, and Leuconostoc mesenteroides (Fig. 1a; detailed microorganism distribution is presented in Table S1). Imagestream $^{\oplus}$ flow cytometry analysis showing a scatterplot of autofluorescence intensity vs. bright field detail intensity of 19,380 events, is presented in Fig. 1b. The flow cytometry data indicate that subpopulations defined as bacterial cells comprised $87 \%$ of the kefir mixture (representative microscopy image of the bacterial cells is depicted in Fig. 1b (i)), fungal cells were approximately $5 \%$ (Fig. 1b (ii)), and the remainder subpopulations of fungi/bacteria aggregates (Fig. 1b (iii-iv)). Detailed event counts are presented in Table S2.

\section{Effect of the kefir on bacterial quorum sensing}

Bioluminescence assays employing reporter strains lacking the gene encoding the enzyme for QS autoinducer synthesis (CAI-1) [17] were performed to determine the effect of the kefir on bacterial QS (Fig. 2). A scheme depicting the principle of the bioluminescence QS analysis is illustrated in Fig. 2a. Essentially, high concentrations of autoinducer molecules bind to specific receptors which consequently activate the intracellular transcription machinery which stimulates expression of bioluminescence genes (i.e., high bioluminescence emission indicates quorum sensing activation in the system).

In the experiments outlined in Fig. 2b, bioluminescent QS reporter strains and the QS autoinducers for each bacterial species [18-20] were incubated in the presence of crude kefir extract, thereby allowing quantitative assessment of QS inhibition or activation. Importantly, Fig. 2b demonstrates that the kefir crude extract interfered with QS pathways of all three bacterial species examined. In case of the Vibrio cholerae MM920 mutant lacking the ability to synthesize its CAI-1 autoinducer, the kefir extract had a significant quorum sensing inhibitory (QSI) effect, as illustrated by the direct correlation between kefir crude extract dilution and attenuation of 


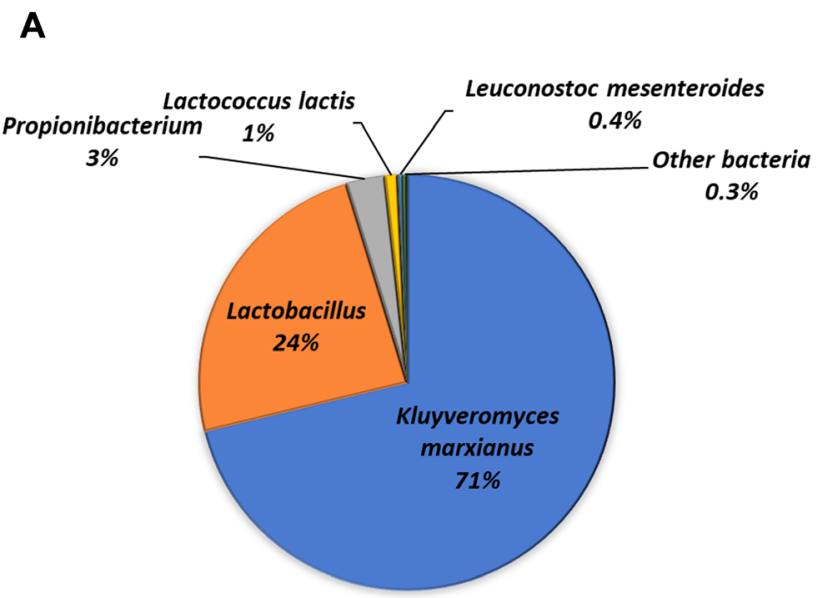

(i)

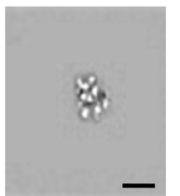

B

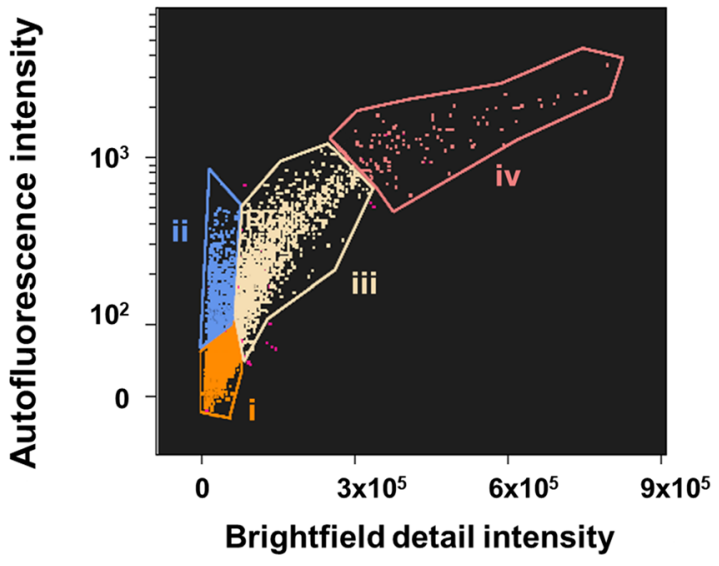

(ii)

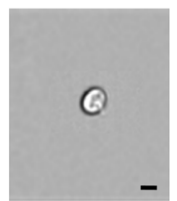

(iv)
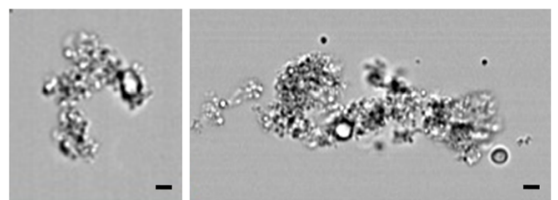

Fig. 1 Microorganism composition of the kefir. a Distribution pie chart of microorganisms in the kefir, obtained through total DNA shotgun sequencing based on a BLAST comparison in the One Codex data platform for applied microbial genomics. b Imagestream ${ }^{\oplus}$ flow cytometry analysis depicting microorganisms size/shape distribution. The dot plot of autofluorescence vs. bright field detail intensities of 19380 events analyzed. The brightfield cell images were used to draw an initial dot plot to identify cells of interest and exclude debris. The populations corresponding to initial hand-picked galleries of images are automatically gated on dot plot and each gate is indicated with a different color. Representative microscopic images of the cell subpopulations presented in the scatterplot: (i) bacterial cells; (ii) fungal cells; (iii-iv) fungal/bacterial cell aggregates. Scale bars correspond to $5 \mu \mathrm{m}$

bioluminescence [the baseline in the graphs in Fig. 2b corresponds to the luminescence recorded upon addition of the autoinducers alone (i.e., no inhibition of QS) $[17,21]$.

The kefir extract similarly had a concentrationdependent QSI effect in case of Agrobacterium tumefaciens A136, in which the QS pathway was induced by its 3-oxo-octanyl homoserine lactone autoinducer [20] (Fig. 2b). Interestingly, the results of the Vibrio harveyi MM30 bioluminescence assay utilizing the (4S)-4,5-dihydroxy-2,3-pentanedione (S-DPD) autoinducer [22] appear to show that the kefir extract induced quorum sensing activation (QSA) in all dilutions (Fig. 2b). In addition, tryptophol acetate did not interfere in the extent of proliferation of $V$. cholerae bacterial cells, nor other bacterial strains tested in this work (e.g., Fig. 2), including $V$. harveyi, A. tumefaciens, and P. aeruginosa (Figures S1, a-c and S2 ). As the bioluminescence assays in Fig. $2 \mathrm{~b}$ indicated that substances in the kefir extract affect QS pathways (inhibition or activation) of different bacteria, we further investigated whether the kefir extract could influence formation of biofilm matrixes assembled by pathogenic bacteria (Fig. 2c). Biofilms are rigid proteinaceous/oligosaccharide matrixes which function as protective layers and virulence factors of diverse bacteria [23].

Importantly, QS cascades are fundamental processes in biofilm formation [24]. Indeed, our results reveal significant inhibitory effect of the kefir extract upon biofilms assembled by the prominent pathogenic bacteria Pseudomonas aeruginosa, Salmonella enterica, and Staphylococcus aureus (Fig. 2c). Notably, the quantitative analyses demonstrate reductions of between 30 and 40\% in biofilm volumes induced by co-incubation of the bacteria with the kefir extract, as compared to untreated bacteria. Cell-viability assays confirmed that the kefir extract did not adversely affect bacterial cell proliferation and viability, thus indicating that disruption of cell-cell communication is the likely factor contributing to kefirinduced biofilm inhibition (Fig. 2d). It should be noted, however, that other constituents in the kefir extract may as well play a role in biofilm inhibition.

\section{Kefir-extracted molecule interferes with Vibrio cholerae communication pathways}

To characterize the molecular constituents in the kefir that contribute to QS interference and disruption, we applied comprehensive screening using column 


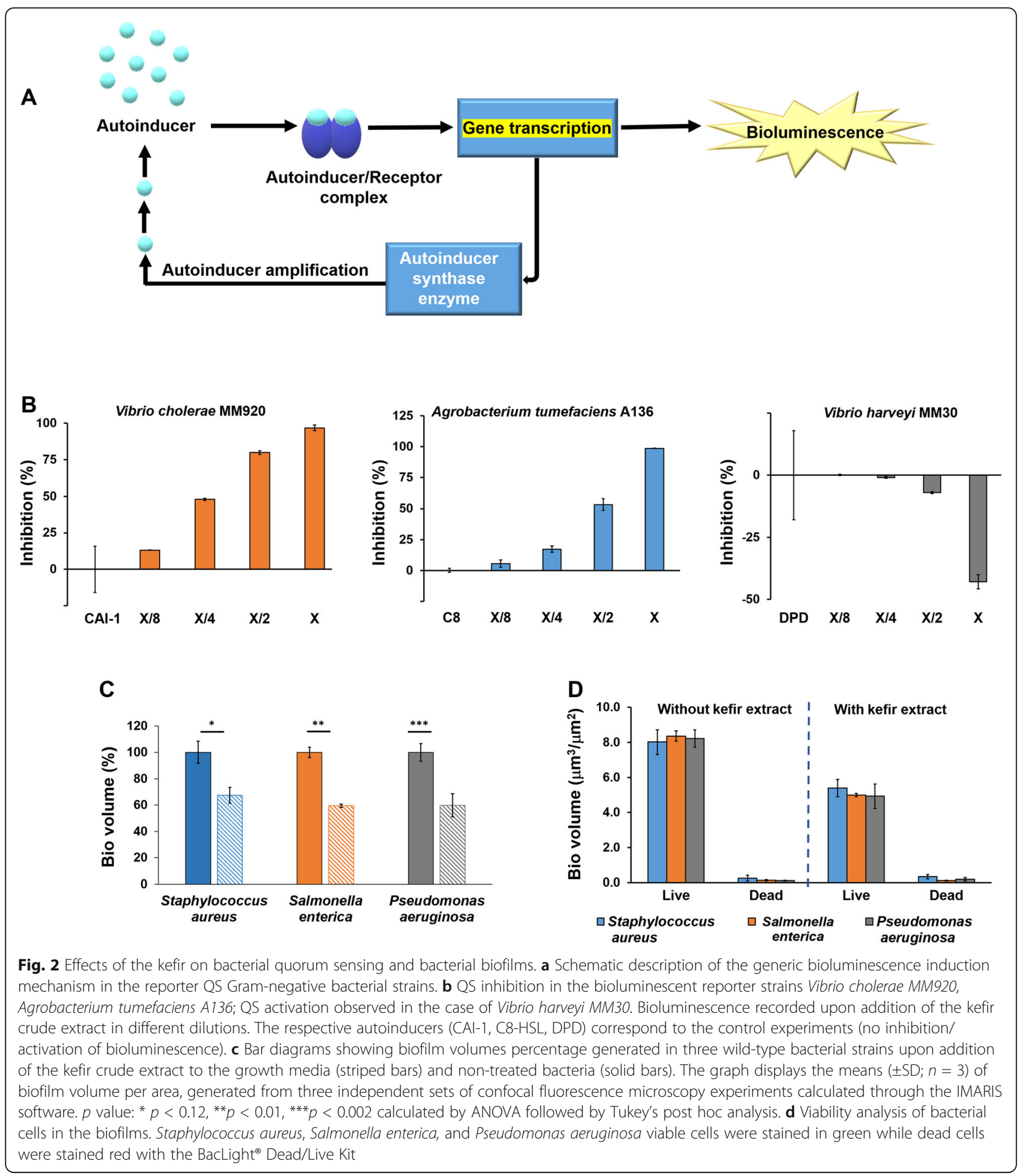

chromatography. The chromatography experiments allowed identification of a small molecule secreted by $K$. marxianus - tryptophol acetate (Fig. 3 and Figure S3) which exhibited remarkable anti-QS activities (Figs. 4 and 5, below). Notably, our focus was on $K$. marxianus metabolites since this fungus was the predominant microorganism constituent in the kefir. High performance liquid chromatography (HPLC) results show the peak ascribed to tryptophol acetate extracted from pure K. marxianus culture (Fig. 3a (i)). A corresponding peak having the same retention time is clearly apparent in the chromatogram of the whole kefir crude extract (Fig. 3a 

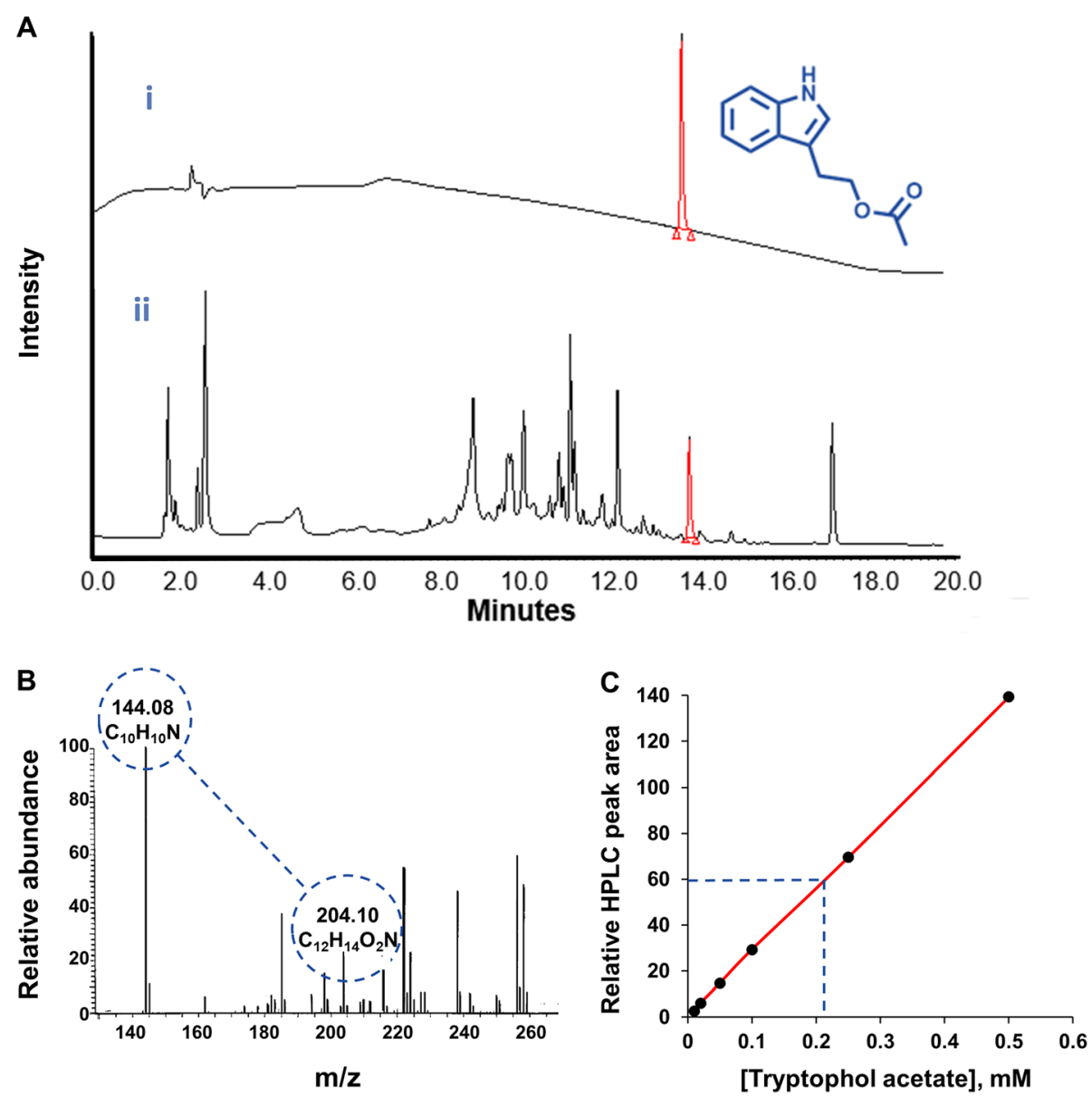

Fig. 3 Identification of tryptophol acetate secreted by Kluyveromyces marxianus. a HPLC chromatogram of (i) tryptophol acetate extracted from the K. marxianus monoculture crude with a retention time of $13.84 \mathrm{~min}$ (peak indicated in red); tryptophol acetate molecular structure is indicated. (ii) Tryptophol acetate identified in the kefir crude extract (peak shown in red at the same retention time). b MS spectrum acquired in positive enhanced mass spectrometry for the identified tryptophol acetate peak in the kefir crude extract (between 13.72 and 14.05 min). c Calibration curve of tryptopol acetate in the kefir crude extract constructed with the synthetic compound. The broken lines indicate the concentration of tryptophol acetate in the kefir extract $(210 \mu \mathrm{M})$

(ii)), indicating that tryptophol acetate was also secreted in the microorganism mixture comprising the kefir.

The molecular weight of the extracted tryptophol acetate was determined by mass spectrometry (MS) in positive ion mode [25], showing $\mathrm{m} / \mathrm{z}$ peaks of 144.08 and 204.10 Da (Fig. 3b). The peak in $\mathrm{m} / \mathrm{z} 144.08$ is due to dissociation of the 204.10 Da molecule, showing a characteristic pattern in the mass spectrum (according to NIST Mass Spectrometry library identification data, ID: 144123). The isolated preparative HPLC fraction was further characterized by gas chromatography-mass spectrometry (GC-MS) and by ${ }^{1} \mathrm{H}$ and ${ }^{13} \mathrm{C}$ spectroscopy (Figure S3), confirming the molecular structure. We further determined that the concentration of tryptophol acetate in the kefir biomass was approximately $210 \mu \mathrm{M}$, based on a calibration curve employing a synthetic tryptophol acetate standard (Fig. 3c). Tryptophol acetate is likely produced through metabolic pathways as derivatives of tryptophol, fungal metabolite participating in fungal cell-cell communication [26].

Following identification of the compound secreted by $K$. marxianus in the kefir, we investigated the specific anti-QS activities of tryptophol acetate in the case of Vibrio cholerae, a major waterborne human gut pathogen [27] (Fig. 4). Tryptophol acetate was synthesized via conventional procedures and its purity (99.9\%) was verified by MS and NMR. The effect of tryptophol acetate on the quorum sensing reporter strain $V$. cholerae MM920, the luminescent $V$. cholerae strain lacking the gene encoding the enzyme for the QS autoinducer CAI1 [17], was determined (Fig. 4a). This strain has been widely employed for studying QS regulation, particularly compounds blocking CqsA, a prominent CAI-1 autoinducer synthase [28]. Indeed, Fig. 4a reveals dramatic concentration-dependent inhibition of $V$. cholerae QS by tryptophol acetate; almost complete blocking of the 


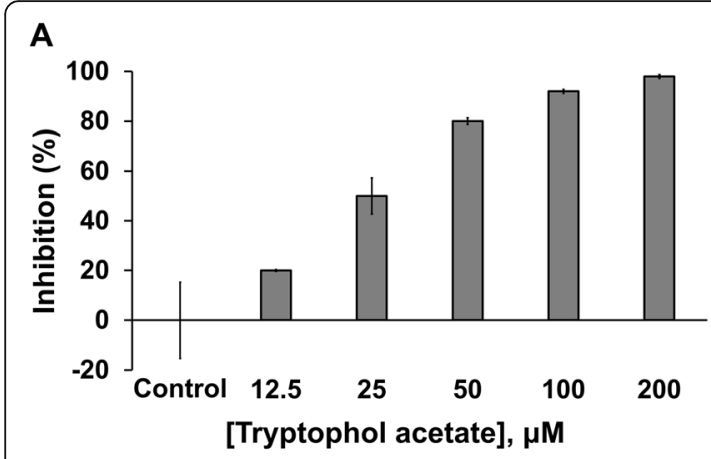

C

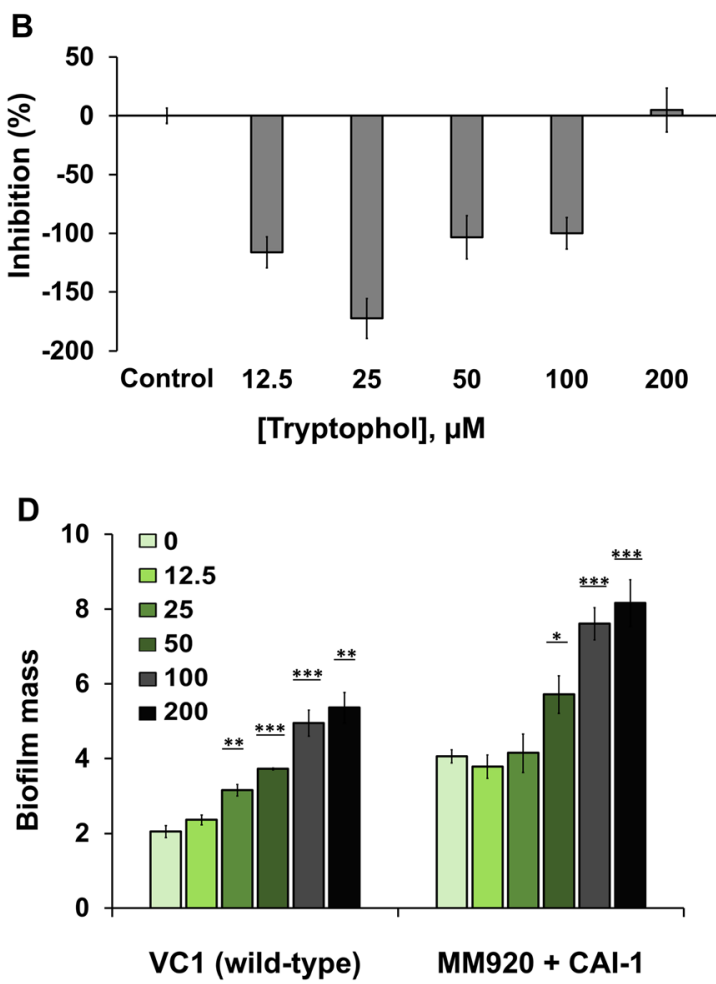

Fig. 4 Effects of tryptophol acetate on Vibrio cholerae quorum sensing and biofilm assembly. a Tryptophol acetate concentration-dependent inhibition of the CAI-1 QS system in V. cholerae MM920. Experiments were performed in triplicate and error bars represent standard deviation of the mean. $\mathbf{b}$ Concentration-dependent effect of tryptophol on the CAl-1 QS system in V. cholerae MM920. Experiments were performed in triplicate and error bars represent standard deviation of the mean. c Confocal fluorescence microscopy z-stacks showing V. cholerae biofilms. Excitations were at $488 \mathrm{~nm}$ and $561 \mathrm{~nm}$; emission 490-588 nm and 604-735 nm, respectively. V. cholerae viable cells were stained in green while dead cells were stained red with the BacLight ${ }^{\oplus}$ Dead/Live Kit. Sizes of the biofilm images are $500 \mu \mathrm{m} \times 500 \mu \mathrm{m}$. (i) V. cholerae VC1 (wild-type); (ii) V. cholerae VC1 grown in the presence of 100 MM tryptophol acetate; (iii) V. cholerae MM920 mutant; (iv) V. cholerae MM920 incubated with 900 nM CAl-1; (v) V. cholerae MM920 incubated with both $900 \mathrm{nM} \mathrm{CAl-1}$ and $100 \mu \mathrm{M}$ tryptophol acetate. The graph (top right) displays the means ( \pm SD) of biofilm volume per area, generated from three independent sets of confocal fluorescence microscopy experiments calculated through the IMARIS software. $\mathbf{d} \mathrm{V}$. cholerae biofilm mass analysis at different concentrations of tryptophol acetate $(\mu \mathrm{M})$ obtained through crystal violet staining (The concentrations in $\mu \mathrm{M}$ are indicated by the different bar colors). Biofilms were stained after 24-hr growth. Error bars indicate the standard deviations of 4 measurements. ${ }^{*} p<0.001,{ }^{* *} p<0.0001$, ${ }^{* * *} p<$ 0.000001 versus the control calculated by ANOVA followed by Tukey's post hoc analysis

CAI-1 QS cascade was apparent upon incubation of the bacteria with $200 \mu \mathrm{M}$ of the compound (the calculated IC50 was $22.8 \pm 3.7 \mu \mathrm{M})$. Moreover, addition of $200 \mu \mathrm{M}$ tryptophol acetate to $V$. cholerae MM920 cultured medium had no appreciable effect on bacterial growth (Figure S1, d). We additionally tested the effect of tryptophol (previously shown to partake in fungal cell communication [26]) upon $V$. cholerae MM920 at a similar concentration range as the tryptophol acetate (Fig. 4b). Importantly, the bar diagram in Fig. $4 \mathrm{~b}$ reveals that, different than tryptophol acetate, tryptophol did not inhibit $V$. cholerae QS, but rather enhanced QS in concentrations lower than $200 \mu \mathrm{M}$. This effect is probably linked to tryptophol being a cell-cell communication molecule in yeasts [26].
The effect of tryptophol acetate on $V$. cholerae biofilms, the crucial component in their proliferation and pathogenicity, is illustrated in Fig. 4c, d. Representative confocal fluorescence microscopy images attest to the significant biofilm enhancement induced by tryptophol acetate, consistent with the anti-QS effect of the compound (e.g., Fig. 4a). In the case of $V$. cholerae VC1 wild-type (WT), the biofilm matrix (without addition of tryptophol acetate) appeared thin and non-uniform (Fig. 4c (i)), ascribed to the reciprocal relationship between functioning QS pathways in the $V$. cholerae $\mathrm{VC1}$ WT strain and assembly of the biofilm matrix by this bacterium [29]. Indeed, contrary to most other pathogenic bacteria, $V$. cholerae responds to the accumulation of QS autoinducers in high cell densities with the 

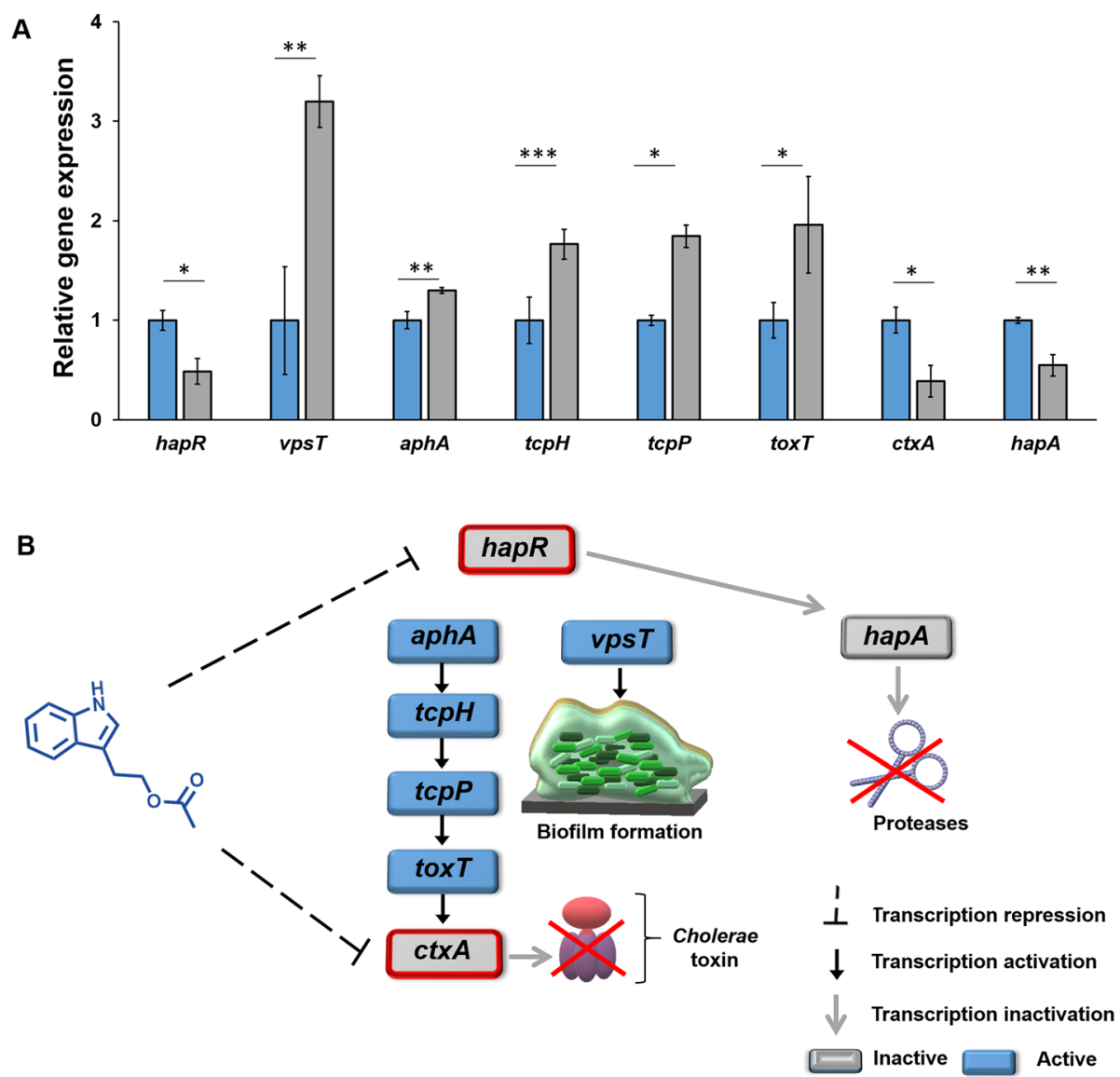

Fig. 5 Effect of tryptophol acetate on the expression of genes associated with quorum sensing in $V$. cholerae. a Relative gene expression in $V$. cholerae VC1 WT assessed by RT-qPCR. The blue bars correspond to bacteria untreated with tryptophol acetate, while the grey bars indicate gene expression levels recorded following addition of the compound. The relative magnitude of gene levels was defined as the copy number of cDNA of genes in the QS pathway normalized in relation to the expression of a reference housekeeping gene not affected by the treatment. Error bars indicate standard deviations of four independent cultures. ${ }^{*} p<0.002,{ }^{* *} p<0.0001,{ }^{* * *} p<0.05$ versus the untreated bacteria calculated by ANOVA followed by Tukey's post hoc analysis. $\mathbf{b}$ Scheme depicting the effects of tryptophol acetate upon QS gene regulation of biofilm formation and virulence of $V$. cholerae in high cell density conditions (as recorded in the RT-qPCR experiments). The solid black arrows indicate transcription activation, the grey arrows indicate inactivation, while the dashed lines account for transcription repression induced by tryptophol acetate. Genes shown in grey background with red borders - hapR and ctXA-were downregulated by tryptophol acetate, while blue backgrounds account for genes that were upregulated due to repression of hapR (mimicking low cell density conditions), see text

repression rather than activation of biofilm formation and virulence factors [29]. A significantly denser biofilm was formed upon incubation of the proliferating bacteria with tryptophol acetate $(100 \mu \mathrm{M}$, Fig. $4 \mathrm{c}$ (ii)). This result is ascribed to inhibition of the QS CAI-1 cascade by tryptophol acetate (e.g., Fig. 4a).

A similar dramatic effect of tryptophol acetate on biofilm assembly is apparent in the case of the $V$. cholerae MM920 mutant (Fig. 4c (iii-v)). The biofilm of the mutant strain alone appeared thick and dense (Fig. 4c (iii)) due to absence of the CAI-1 QS cascade [17]. However, addition of the CAI-1 autoinducer to the bacterial growth medium reintroduced QS thereby disrupting biofilm uniformity and integrity (Fig. 4c (iv)). Notably, co- addition of tryptophol acetate and CAI-1 gave rise to a dense and uniform biofilm layer (Fig. 4c (v)), reflecting inhibition of CAI QS pathway.

The variations in biofilm volumes apparent in the fluorescent microscopy images in Fig. 4c (i-v) are illustrated quantitatively (through application of 3D visualization processed using IMARIS software) in the bar diagram in Fig. 4c, top right. Dose-response biofilm mass analysis carried out through application of the crystal violet (CV) assay [30], depicted in Fig. 4d, corroborates the fluorescence microscopy (Fig. 4c), providing additional evidence for QS inhibition by tryptophol acetate. Overall, given the fact that activation of QS in $V$. cholerae leads to reduced biofilm formation, the 
increased biofilm volumes and mass recorded upon addition of tryptophol acetate indicate that the molecule affects direct inhibition of QS pathways in $V$. cholerae.

\section{Modulation of quorum sensing genetic pathways of $V$. cholerae by tryptophol acetate}

Since enhanced biofilm generation by $V$. cholerae goes together with increasing virulence of this pathogenic bacterial species (primarily secretion of the cholerae toxin, CT) [31], we investigated the effect of tryptophol acetate upon the genetic mechanisms associated with QS and virulence in $V$. cholerae. Accordingly, we carried out real time-quantitative PCR (RT-qPCR) analysis evaluating gene expression of $V$. cholerae VC1 WT in high cell density conditions (Fig. 5). Indeed, the RTqPCR results provide evidence for specific effects of tryptophol acetate (at a concentration of $100 \mu \mathrm{M}$ ) on genes associated with QS, biofilm, and virulence regulation of $V$. cholerae (the pertinent gene cascade and the effects of tryptophol acetate on gene regulation are shown in Fig. 5b), accounting for the phenotypic changes induced by the compound (i.e., Fig. 4). Specifically, the RT-qPCR results in Fig. 5a indicate significant downregulation of $h a p R$ by tryptophol acetate. This result is notable, since hapR repression occurs at low cell density conditions [32,33] (gene regulation pathways of $V$. cholerae in low and high cell densities, respectively, are presented in Figure S4). Thus, mimicking low cell density through $h a p R$ downregulation may account for the enhanced biofilm generation [29, 34] as observed upon incubation of $V$. cholerae with tryptophol acetate (i.e., Fig. 4b, d).

Repression of hapR is also consistent with the reduced bioluminescence occurring upon incubating tryptophol acetate with $V$. cholerae MM920 (Figs. 2a and 4a) since the luciferase is associated with expression of this gene [35]. Lower expression of hapR further accounts for the significant upregulation of $v p s T$ by tryptophol acetate (Fig. 5a, cascade shown in Fig. 5b). Interestingly, tryptophol acetate also reduced expression of hapA (Fig. 5a), a downstream gene regulated by hapR [36]. Downregulation of hapA may also point to potential therapeutic benefits of the kefir, since the HapA protein is associated with a variety of adverse symptoms induced by $V$. cholerae, such as fluid generation and diarrhea [33]. Additional regulatory effects of tryptophol acetate on other gene and protein constituents of QS pathways in V. cholerae may occur.

Mimicking low cell density for $V$. cholerae following addition of tryptophol acetate is expected to promote genetic cascades leading to enhanced virulence [36] (i.e., upregulation of the genes in the aphA pathway, Fig. 5b). Indeed, the RT-qPCR experiment in Fig. 5a demonstrates that tryptophol acetate induced upregulation of aphA,
tcpP, tcpH, and toxT associated with $V$. cholerae toxin production. Surprisingly, however, $\operatorname{ctx} A$, a virulenceinducing gene that is downstream in the aphA-induced virulence cascade [37], was in fact significantly repressed by tryptophol acetate (Fig. 5a).

$\operatorname{ctx} A$ downregulation together with repression of hapR by tryptophol acetate (Fig. 5) may have significant physiological implications as lower pathogenicity and virulence of $V$. cholerae. Accordingly, we further examined the effect of tryptophol acetate upon $V$. cholerae virulence. Figure 6 examines the production of the B subunit of the cholerae toxin (CTB)-the virulence factor of $V$. cholerae regulated by $\operatorname{ctx} A$ [38]. Figure $6 a$ shows western immunoblotting performed on VC1 WT strain cultured either in the presence or absence of $100 \mu \mathrm{M}$ tryptophol acetate (no autoinducer added since the experiment utilized the wild-type strain). Indeed, the representative western blot in Fig. 6a demonstrates that the expression of CTB was significantly inhibited in the presence of tryptophol acetate in the medium. An ELISA assay for CTB production using GM1 (the CTB receptor) from filtered supernatant of wildtype V. cholerae (Fig. 6b) similarly attests to a direct relationship between tryptophol acetate inhibition and toxin secretion by the bacteria.

The confocal fluorescence microscopy images in Fig. 6c illuminate the extent of CTB secretion by $V$. cholerae through binding of the toxin onto the surface of HeLa cells. In the experiments, the HeLa cells were incubated with CTB extracted from VC1 WT strain cell lysate, in the absence and presence of 100 $\mu \mathrm{M}$ tryptophol acetate. The cells were incubated for two hours with the toxins to allow binding to the cell-surface GM1 receptors, and subsequently stained with a fluorescently labeled monoclonal anti-CTB antibodies. The confocal fluorescence microscopy images in Fig. 6c (middle column) clearly show that cell medium obtained from $V$. cholerae bacteria treated with tryptophol acetate contained much lower concentration of CTB (i.e., significantly less staining upon incubation with CTB-antibody, Fig. 6c (ii)).

Tryptophol acetate induced inhibition of CTB secretion was further dramatically manifested by the cell viability assay in Fig. 6d. In the experiment, HeLa cells were transfected with CTX extracted from $V$. cholerae VC1 WT strain grown with or without tryptophol acetate (100 $\mu \mathrm{M}$ concentration), and subsequently co-labeled with the fluorescence markers SYTO 9 (green, staining live cells), and propidium iodide (PI, which stains dead cells in red). As apparent in the confocal fluorescence microscopy images in Fig. 6d, while significant cell death was induced by medium extracted from the control $V$. cholerae growth (abundant red staining, Fig. 6d (i)), dramatically lower cell death was recorded in HeLa cells 




Fig. 6 Effect of tryptophol acetate on $V$. cholerae toxin secretion. a Cholerae Toxin B (CTB) level expression analyzed by anti-CTB western blotting. $V$. cholerae bacterial cells (VC1 WT strain) were cultured for $16 \mathrm{~h}$ at $30^{\circ} \mathrm{C}$ without tryptophol acetate, and in the presence of $100 \mu \mathrm{M}$ tryptophol acetate. The treated and untreated bacterial cultures were used to isolate the CTB (see "Methods" section). The samples were immunoblotted for CTB protein levels. Beta-actin used as loading control. b V. cholerae toxin production upon adding different concentrations of tryptophol acetate to the $V$. cholerae growing medium quantified with ELISA assay for CTX using GM-1 (the CTX receptor). The $Y$ axis corresponds to percentage of CTX production in the growing medium. Error bars indicate standard deviations of four independent cultures. ${ }^{*} p<0.0001$, versus the untreated bacteria calculated by ANOVA followed by Tukey's post hoc analysis. c Confocal fluorescence microscopy images of HeLa cells grown for $16 \mathrm{~h}$ and exposed to extraction from VC1 WT cell lysate in the absence (i) and presence (ii) of $100 \mu \mathrm{M}$ tryptophol acetate for $2 \mathrm{~h}$. Cells were fixed and labeled with monoclonal anti-cholerae toxin, subunit B antibodies (red-excitations were at 633; emission $681 \mathrm{~nm}$ ) and imaged. Nuclei were visualized upon co-staining of the cells with Hoechst 33342 (blue-excitations were at $405 \mathrm{~nm}$; emission $445 \mathrm{~nm}$ ). Individual channels and merged confocal images are shown. Scale bar: $50 \mu \mathrm{m}$. d Confocal fluorescence microscopy images showing the effects of CT extracted from VC1 WT cell lysate; cells were grown in the absence and presence of $100 \mu \mathrm{M}$ tryptophol acetate. The HeLa cells were treated with $\mathrm{CT}$ for $16 \mathrm{~h}$ at $37^{\circ} \mathrm{C}$ and $\mathrm{CO}_{2}$ conditions. Propidium iodide staining (red) indicates dead cells and Syto 9 staining (green) indicates viable cells. Excitations were at $488 \mathrm{~nm}$ and $561 \mathrm{~nm}$; emission 490-588 nm and 604-735 nm, respectively. (i) Viability staining of HeLa cells exposed to CT. (ii) Viability staining of HeLa cells exposed to CT under treatment of $100 \mu \mathrm{M}$ tryptophol acetate. Scale bar: $100 \mu \mathrm{m}$

transfected with a medium extracted from $V$. cholerae treated with tryptophol acetate (Fig. 6d (ii)). Together, the experiments depicted in Fig. 6 demonstrate that tryptophol acetate significantly reduced CTB secretion by $V$. cholerae, corroborating the genetic analysis in Fig. 5, and underscoring a remarkable virulence inhibition effect by the K. marxianus-secreted compound.

\section{Conclusions}

This study reports interference with quorum sensing pathways in human pathogens induced by a probiotic yeast- $K$. marxianus. We identified a specific compound-tryptophol- acetate-secreted by $K$. marxianus, which disrupted CAI-1 QS cascades in $V$. cholerae, significantly modified $V$. cholerae biofilm formation and morphology, and reduced bacterial virulence. These phenotypic effects are ascribed to upregulation or downregulation of genes associated with the QS cascades of $V$. cholerae. These results are notable, since this is the first demonstration that QS in human pathogenic bacteria can be modulated by molecules secreted by probiotic yeast. Furthermore, tryptophol acetate has not been associated previously with bacterial QS attenuation. Our findings suggest that distinct symbioses in multi-microorganism populations may be maintained by secreted QS-modulating 
molecules. Such cross-kingdom QS interfering molecules may play important roles both in fermented milk products, in the digestive system of a person consuming the mixtures, and possibly also in the gut microbiome in general. These potentially universal effects may account for pathogencombating properties of the human microbiome and could aid elucidating health benefits of probiotic microorganism products.

\section{Methods}

\section{General information}

The solvents Ethyl acetate (EA) and dichloromethane (DCM) were purchased from Biolab (Israel). Hexane, DMSO, Dulbecco's phosphate-buffered saline (PBS X1), Trifluoroacetic acid (TFA), Petroleum ether (PE), and bovine serum albumin (BSA) were purchased from Sigma-Aldrich. Formic acid HPLC grade was purchased from Supelco. Bacterial and cells media: Lennox LB broth (L3022, Sigma-Aldrich); Miller LB broth (L3522, Sigma-Aldrich); Dulbecco's modified Eagle's Medium (DMEM, D5796, Sigma-Aldrich).

\section{Kefir culturing}

The kefir grains were offered originally by a private household that agreed to use them in this study. In the laboratory, $50 \mathrm{~g}$ of the kefir grains inoculated into a $1000 \mathrm{~mL}$ flask containing $800 \mathrm{~mL}$ of pasteurized cow milk was covered with sterile gauze. The mixture was subsequently cultivated at $28{ }^{\circ} \mathrm{C}$ for 24 h. Subsequently, the kefir was filtered to separate the grains from the fermented milk. The cultured microorganisms were sent for sequence analysis. To generate biomass crude extract of the kefir, the fermented milk was centrifuged at $1100 \times g$ for $10 \mathrm{~min}$ to separate the precipitate and supernatant. Five hundred milliliters of the supernatant was then moved to a separating funnel and mixed with 500 $\mathrm{mL}$ EA. The organic phase was separated from the supernatant and transferred to a round bottom flask to evaporate all the solvent until a solid residue was obtained, containing the kefir organic molecules. The extraction was repeated three times.

\section{All metagenome sequencing of the kefir}

Genomic DNA from kefir cultures was extracted using a PowerSoil $^{\odot}$ DNA Isolation Kit (MoBio Laboratories, Loker Avenue West Carlsbad, CA, USA), according to the manufacturer's instructions. Total DNA was sent to DNA Services (DNAS) Facility, at the Research Resources Center, the University of Illinois at Chicago (UIC) for shotgun sequencing. Sequences method Nextera XT with the sequence of paired-end $2 \times 150$ reads illumine Nex-Keg 500 sequencer was performed. The reads were uploaded as FASTQ to One Codex website and were analyzed for metagenomics taxonomic annotation results.

\section{Microbial culturing}

Kluyveromyces marxianus strain HA 63 [ATCC, NRRL Y-8281, CBS 712] was cultured in $300 \mathrm{~mL}$ of yeast malt broth (Y3752, Merck) and grown at $30{ }^{\circ} \mathrm{C}$ for $24 \mathrm{~h}$ and agitation at $100 \mathrm{rpm}$.

Agrobacterium tumefaciens A136 ( $\Delta \mathrm{Ti}$ plasmid) containing plasmids pCF218 (overexpressing the TraR protein, which activates the traI fusions in response to $\mathrm{N}$ acyl-homoserine lactones) and pMV26 which contains the traI promoter fused to the luxCDABE operon of $V$. harveyi [39]. Bacterial culture was grown in Luria-Bertani broth (LB; Miller's broth) supplemented with $25 \mu \mathrm{g} /$ $\mathrm{mL}$ of kanamycin and $4.5 \mu \mathrm{g} / \mathrm{mL}$ of tetracycline at 28 $-30{ }^{\circ} \mathrm{C}$ for $24 \mathrm{~h}$.

Vibrio harveyi strain MM30 [40] and Vibrio cholerae strain MM920 ( $\Delta c q s A, \Delta l u x Q$, pBB1) [17] were grown in LB Broth (Lennox) supplemented with $5 \mathrm{mg} / \mathrm{L}$ tetracycline at $30{ }^{\circ} \mathrm{C}$ for $24 \mathrm{~h}$.

Vibrio cholerae VC1 wild-type strain was grown in LB Broth (Lennox) at $30{ }^{\circ} \mathrm{C}$ for $24 \mathrm{~h}$; Staphylococcus aureus wild-type group IV strain [41], Salmonella enterica ATCC 13076 [42], and Pseudomonas aeruginosa PA01 wild-type strain [42] were incubated for $24 \mathrm{~h}$ in LB broth medium at $37^{\circ} \mathrm{C}$.

All the bacterial strains and autoinducers that activate their QS systems (CAI-1; C8-HSL and DPD) were provided by Prof. Michael M. Meijler, Ben Gurion University of the Negev, Israel.

\section{Imaging flow cytometry}

The kefir was diluted 1:10 with water and analyzed by Image Stream X Mk II (Amnis Corporation, Seattle, WA, USA). The initial identification of in-focus images of microorganisms was conducted using the system default mask of bright-field and gradient root mean square scores. The software uses algorithms based on the pixel intensity and variation in an object image frame; essentially, the algorithm employs pixel intensity to spatially distinguish the microorganism's cells from the surrounding background [43]. A default mask of BF (Bright field) was used to identify the microorganisms in focus and plot the Gradient root mean square (RMS). For calculating the count values, a costume mask was applied to the fungal cells on the auto fluorescence channel (excitation at $488 \mathrm{~nm}$; emission at 505-560 nm). Then, according to the intensity values calculated by the instrument, the microorganisms were divided into subpopulations.

Extraction of Kluyveromyces marxianus-secreted molecules Kluyveromyces marxianus culture was centrifuged at $1100 \times g$ for $10 \mathrm{~min}$, and the supernatant was collected. 
The supernatant was then moved to a separating funnel and mixed with an equivalent volume of EA for the extraction. The blend was shaken for $10 \mathrm{~min}$, the organic phase was transferred to a new tube, and the extraction was repeated three times. Next, the extracts were evaporated to remove all fluids and finally dried at the lyophilizer to remove water.

\section{Isolation of tryptophol acetate}

Flash chromatography was performed using Merck 40$63 \mu \mathrm{m}$ silica gel and appropriate solvent based on thin layer chromatography (TLC). TLC (using Silica gel 60 $\mathrm{F}_{254}$ plates, Merck) was carried out using Hexane:EA 70: 30 (v/v) solvent mixture; fractions displaying suitable Rf of 0.35 (e.g., containing tryptophol acetate) were selected. Preparative HPLC was performed by a Dionex Ultimate 3000 instrument (Thermo Scientific) using a Luna C18 column, $10 \mu \mathrm{m}(250 \times 21.20 \mathrm{~mm})$, at a flow rate of $25 \mathrm{~mL} / \mathrm{min}$. All runs used linear gradients of $0.1 \%$ aqueous TFA (solvent A) vs $90 \%$ acetonitrile containing $0.1 \%$ TFA (solvent B). The compound was identified by UV detection at a single wavelength $(240 \mathrm{~nm})$.

\section{Liquid chromatography-mass spectrometry (LC-MS)}

The kefir biomass crude extract was dissolved in Acetonitrile and injected to LC-MS to identify molecules that originated from the Kluyveromyces marxianus metabolism. The molecular weight was determined by MS using an LTQ XL Orbitrap with a static nanospray in positive ion mode (Waters Acquity QDA with PDA and QDA detectors) analyzed by Xcalibur and Process software (Thermo Scientific). For LC/MS analyses, a Surveyor Plus HPLC System (Thermo Scientific) was used, equipped with a Luna C18, $5 \mu \mathrm{m}(150 \times 4.6 \mathrm{~mm})$ column at a flow rate of $0.5 \mathrm{~mL} / \mathrm{min}$, using a mobile phase linear gradient of $0.1 \%$ aqueous formic acid (solvent A) and acetonitrile containing $0.1 \%$ formic acid (solvent B). Additionally, quantitative determination of tryptophol acetate concentration in the kefir biomass crude extract was implemented. To do so, we diluted the Tryptophol acetate at six concentrations: 0.01, 0.02, 0.05, 0.1, 0.25, and $0.50 \mathrm{mM}$ to generate a calibration curve. We produced a plot of tryptophol acetate peak area vs. concentration and the plot showed a linear relationship.

\section{Gas chromatography-mass spectrometry (GC-MS)}

The kefir biomass crude extract was dissolved in Acetonitrile and injected to Thermo Scientific GC-MS with Trace GC ultra and ITQ with RTX-5 $0.25 \mathrm{~mm} \times 0.25$ $\mathrm{mm} \times 30 \mathrm{~m}$ column to identify molecules that originated from the Kluyveromyces marxianus metabolism.

\section{Procedure for synthesis of tryptophol acetate [44] General information}

All the reactions were carried out under the air atmosphere in flame-dried glassware. Syringes were used to transfer anhydrous solvents and liquid chemical reagents. Column chromatographical purifications were performed using SiO2 (120-200 mesh ASTM) purchased from Merck. Tryptophol (indole 3-ethanol) was purchased from Alfa Aesar. Triethyl amine, acetyl chloride, acetic anhydride, and P-toluene sulfonic acid were purchased from Sigma-Aldrich. Above chemicals were used without further purification.

To a stirred solution of tryptophol ( $5 \mathrm{mmol}, 1.0$ equiv), Tryethylamine $(1.4 \mathrm{~mL}, 10 \mathrm{mmol}, 2.0$ equiv) in dry DCM $(10 \mathrm{~mL})$, acetic anhydride $(0.4 \mathrm{~mL}, 6 \mathrm{mmol}, 1.2$ equiv) was added in a drop wise at room temperature and further the reaction mixture was stirred at room temperature for $12 \mathrm{~h}$.

After completion, the reaction mixture was quenched by water $(5 \mathrm{~mL})$ and the resulting residue was extracted with ethyl acetate (10 mL, 3 times). The combined organic layers were washed with brine (5\% sodium chloride (Merck) in water), dried over anhydrous $\mathrm{Na} 2 \mathrm{SO} 4$ (Sigma-Aldrich), and concentrated under reduced pressure. Further purification by silica gel column chromatography using hexane/Ethyl acetate (4:1) as the eluent provided the desired product as a colorless solid. The product was confirmed by comparing their ${ }^{1} \mathrm{H}$ NMR data with those reported in previous literature $(893 \mathrm{mg}$; purity $99.9 \%$ ).

\section{Determination of quorum sensing activity}

The effects of the Kefir biomass crude extract molecule on the following bacteria, A. tumefaciens A136, V. cholerae MM920 and $V$. harveyi MM30 were assessed as described by Brenier et al. [22]. All the strains were cultured as described in the bacterial culturing section. Each culture was diluted to an absorbance density (OD600) of 0.05 by the appropriate fresh LB medium (Lennox). A clear bottom 96-well microliter plate (Thermo Scientific, Rochester, NY, USA) was prepared with wells containing test compound serially diluted into the LB medium starting with the concentration of 200 $\mu \mathrm{M}$ to $12.5 \mu \mathrm{M}$. A total of $100 \mu \mathrm{L}$ of the diluted cultured cells was added to each well. The control sample contained the bacteria and specific autoinducer molecules without containing the tested compound. Luminescence was measured every $20 \mathrm{~min}$ for $19 \mathrm{~h}$ with continuous shaking at $30{ }^{\circ} \mathrm{C}$, using a Microtiter Plate Reader (Varioskan Flash, Thermo). Two types of experiments were performed: a competition assay in the presence of 400 pM 3-oxo-C8-HSL (A. tumefaciens A136), $900 \mathrm{nM}$ CAI-1 (V. cholerae MM920), 200 nM (R)-4,5-dihydroxy2,3-pentanedione (DPD) ( $V$. harveyi MM30) and assay 
in the absence of these AI's. This allowed measuring agonistic activity of the crude-extracted molecule. Average luminescence values divided by OD600 values were plotted against the added compound concentrations.

\section{Biofilm modulation activity of kefir biomass crude extract molecules}

P. aeruginosa PA01, Salmonella enterica, and Staphylococcus aureus strains were incubated for $24 \mathrm{~h}$ at $37^{\circ} \mathrm{C}$. The bacterial suspensions were diluted 1:10 with fresh LB and incubated for $3 \mathrm{~h}$ with the kefir biomass crude extract molecules or with DMSO as a control (refreshment samples). In all cultures, DMSO concentration was up to $1 \%$. Two hundred microliters of the broth medium mix with yogurt extract or with DMSO as control was placed in each well of a 96-well plate (Thermo Scientific, Rochester, NY, USA). Two microliters of refreshment samples was added to each suitable well. The plate incubated for $24 \mathrm{~h}$ at $37{ }^{\circ} \mathrm{C}$. After the incubation, the samples washed three times with PBS. For visualizing of viable cells, the bacteria were stained using the BacLight ${ }^{\circ}$ Dead/Live Kit (Invitrogen, Eugene, OR, USA). This resulted in live cells staining green and dead cells stained red. The stained cells were washed twice with PBS. Biofilm images were taken by CLSM (Olympus, Tokyo, Japan). Image processing was done using IMARIS software (Bitplane, Zurich, Switzerland).

\section{Biofilm modulation activity of synthetic tryptophol acetate}

For the static biofilm assay, overnight cultures of $V$. cholerae strain MM920 were diluted 1:10 in fresh LB medium (Lennox) containing a final concentration of $100 \mu \mathrm{M}$ Tryptophol acetate or DMSO (up to 1\%) as a control. We analyzed two types of samples, one in absence of the $V$. cholerae autoinducer (CAI-1) and the other one in the presence of 900 nM CAI-1.

Biofilms were grown under static (non-shaking) conditions at $30{ }^{\circ} \mathrm{C}$ in 96 -well plates (Thermo Scientific, Rochester, NY, USA). The use of the synthesized molecules did not adversely impact cell growth by visualizing viable cells stained green and dead cells stained red with the BacLight ${ }^{\circ}$ Dead/Live Kit (Invitrogen, Eugene, OR, USA). Specifically, no increase in dead cells was observed in the presence of the synthesized molecule compared to control biofilms. The stained cells were washed twice with PBS. Biofilm images were taken by CLSM (Plan-Apochromat 20×/0.8 M27, Zeiss LSM880, Germany).

\section{Real-time quantitative PCR (RT-qPCR) analysis}

RNA was extracted from wild-type strain VC1 cultured in LB medium (Lennox) supplemented with or without $100 \mu \mathrm{M}$ Tryptophol acetate grown to approximately $1.0 \mathrm{OD}(600 \mathrm{~nm})$ using the RNA Protect Bacteria reagent and the $\mathrm{RNeasy}^{\circ}$ Mini Kit (Qiagen, Valencia, CA, USA) as per the manufacturer's instructions, including the oncolumn DNase I digestion described by the manufacturer. Purified RNA was quantified using a Banalyzer (Eppendorf, Hamburg, Germany). cDNA was synthesized from $1 \mu \mathrm{g}$ of RNA using PrimeScriptTM RT reagent kit (Takara, Ohtsu, Japan). The reaction was incubated at $37{ }^{\circ} \mathrm{C}$ for $30 \mathrm{~min}$, and $2 \mu \mathrm{l}$ of cDNA was subjected to RT-PCR analysis on an AB Step One Plus PCR system (Applied Biosystems, Carlsbad, CA), using qPCRBIO SyGreen Blue mix Hi-ROX (PCR Biosystems, London, UK). RT-PCR was performed in a 96-well plate (Bio-Rad) in triplicate in a $20-\mu l$ volume. The $m d h$ gene, regulating malate dehydrogenase catalysis, was used as an endogenous loading control for the reactions. The amount of transcript was analyzed with StepOnePlus Software V2.3 (Applied Biosystems Carlsbad, CA, USA). The primers used for RT-qPCR of endogenous reference gene and target genes are listed in Table 1 (Database accession number from complete genome GenBank: AE003852.1 and NZ_CP028828.1).

\section{Cholera toxin (CT) detection using GM1-ELISA assay}

GM1 (monosialotetrahexosylganglioside) was seeded and immobilized on 96-well white/clear bottom microtiter plate (Greiner) microtiter plates with the following procedure: GM1 stock solution (2 $\mathrm{mg} / \mathrm{mL}$ in PBS) was diluted with PBS (final conc. $10 \mu \mathrm{g} / \mathrm{mL}$ ). Two hundred microliters of the GM1 solution was added to each well and incubated at $37{ }^{\circ} \mathrm{C}$ without shaking for 4-16 h. The plates were washed with PBS $(\times 3)$. Bovine serum albumin (BSA) was dissolved in PBS (final conc. $4 \mathrm{mg} / \mathrm{mL}$ ) and $200 \mu \mathrm{L}$ of the BSA-PBS was added to each well and incubated at $37{ }^{\circ} \mathrm{C}$ without shaking for at least $4 \mathrm{~h}$. The plates were washed with PBS $(\times 3)$ and were stored in fridge until use. VC1 wild-type strain with the tested compound (Tryptophol acetate in a concentration of $100 \mu \mathrm{M})$ and a control with only bacteria were grown and incubated with aeration and shaking overnight in LB medium at $30{ }^{\circ} \mathrm{C}$. The cultures were spanned-down for $5 \mathrm{~min}$ at $5000 \times \mathrm{g}$ and the supernatant was taken and diluted 1:2 with a BSA-PBS $4 \mathrm{mg} / \mathrm{mL}$ solution. Two hundred microliters of the diluted supernatant was added in six-replicates to each GM1 coated well and the plate was incubated at $37{ }^{\circ} \mathrm{C}$ with gentle shaking for at least $30 \mathrm{~min}$. The plates were washed with PBS $(\times 3)$, $200 \mu \mathrm{L}$ of the rabbit antitoxin serum solution (stock solution diluted 1:999 with BSA-PBS) were added to each well and the plate was incubated at $37{ }^{\circ} \mathrm{C}$ with gentle shaking for at least $30 \mathrm{~min}$. The plates were washed with PBS ( $\times 3$ ), $200 \mu \mathrm{L}$ of the IgG solution (goat anti-rabbit immunoglobulin G (IgG) H\&L alkaline phosphatase stock solution (1 $\mathrm{mg} / \mathrm{mL}$ in DDW) was diluted 1:1499 with BSA-PBS) were added to each well and the plate 
Table 1 Primers used for RT-qPCR of endogenous reference gene and target genes

\begin{tabular}{|c|c|c|c|}
\hline Gene & Function & Forward sequences $\left(5^{\prime}-3^{\prime}\right)$ & Reverse sequences $\left(5^{\prime}-3^{\prime}\right)$ \\
\hline$m d h$ & Regulate malate dehydrogenase & CTGGCGGCATTGGTCAAGCCC & ACCCGGTGTGACAGGCGCAA \\
\hline vpsT & Vibrio polysacchaired transcriptional regulator & CGCAGTATTCAGATGCTGGTG & GACCTCTITCGCATCAGGACA \\
\hline$c t \times A$ & Cholerae toxin subunit A & AGCAGTCAGGTGGTCTTATGC & CCCGTCTGAGTTCCTCTTGC \\
\hline$a p h A$ & Virulence gene regulator & ACCGGGTACGATATAACCAAAGAG & GATGGCTGGCTTTCCAGAAG \\
\hline toxt & Transcription activator of virulence genes & TGACGCATACCCATCGACAG & TCACCAGCTAAAAGCCGAGC \\
\hline$t c p H$ & Toxin-co-regulated pilus & TGTTTGGCTTACCCAGACCG & TTCTGAGAGCTAGGATCTGGC \\
\hline tcpP & Toxin-co-regulated pilus & ATTGCATATCAGTCTGGGTTTGC & TCACTTGGTGCTACATTCATGG \\
\hline
\end{tabular}

was incubated at $37{ }^{\circ} \mathrm{C}$ with gentle shaking for at least $30 \mathrm{~min}$. Luminol working solution was prepared by making two stock solutions. Stock A was prepared by adding $0.1 \mathrm{~mL}$ luminol $250 \mathrm{mM}$ in DMSO, $44 \mu \mathrm{L}$ coumaric acid $90 \mathrm{mM}$ in DMSO, $1 \mathrm{~mL}$ tris- $\mathrm{HCl} 1 \mathrm{M} \mathrm{pH}=8.5$ and DDW up to a final volume of $10 \mathrm{~mL}$. Stock B was prepared by adding $6.4 \mu \mathrm{l}$ hydrogen peroxide $30 \%, 1 \mathrm{ml}$ Tris- $\mathrm{HCl} 1 \mathrm{M} \mathrm{pH}=8.5$ and DDW up to a final volume of $10 \mathrm{~mL}$. The plates were washed with PBS $(\times 3)$ and quickly equal volumes of stocks $\mathrm{A}$ and $\mathrm{B}$ were mixed making the luminol working solution. One hundred microliters of the luminol-working solution was added to each well; the plate was shaken for 1.5-2 min and the luminescence was measured using a Microtiter Plate Reader (Varioskan Flash, Thermo).

\section{Cholerae toxin expression and its cytotoxicity for HeLa cells \\ Western blot analysis}

$V$. cholerae (VC1) cells were grown with or without the presence of $100 \mu \mathrm{M}$ tryptophol acetate at $30{ }^{\circ} \mathrm{C}$ for $16 \mathrm{~h}$. Culture supernatants were obtained by centrifugation of these cultures at $1100 \mathrm{xg}$ for $10 \mathrm{~min}$. The cell pellets lysed using $\times 5$ Sample buffer $(125 \mathrm{mM}$ Tris, $0.25 \%$ BPB, 10\% 2-Mercaptoethanol, 10\% SDS, 50\% Glycerol; GenScript, Piscataway, USA) for $5 \mathrm{~min}$ at $95^{\circ} \mathrm{C}$.

Protein concentrations for the analyzed cells extract samples were determined using Bio-Rad protein assay and then separated by SDS-PAGE and transferred to a polyvinylidene difluoride membrane using a transfer apparatus according to the manufacturer protocols (BioRad). After incubation with 5\% skim milk in TBST (10 $\mathrm{mM}$ Tris, $\mathrm{pH}$ 8.0, $150 \mathrm{mM} \mathrm{NaCl}, 0.5 \%$ Tween 20) for 60 min, the membrane was washed once with TBST and incubated with primary goat anti-cholerae toxin sub unit B (1:500; 227040, Sigma-Aldrich) for $16 \mathrm{~h}$ at $4{ }^{\circ} \mathrm{C}$. Membranes were washed three times for $10 \mathrm{~min}$ and incubated with a 1:5000 dilution of horseradish peroxidaseconjugated anti-goat secondary antibodies for $1 \mathrm{~h}$ at room temperature (A50-101P, Bethyl Laboratories, Montgomery, USA). Beta-actin used as loading control (1:1000, MP Biomedicals, Santa Ana, CA, USA). Blots were washed three times with TBST and developed with the ECL system (Amersham Biosciences) according to the manufacturer's protocols.

\section{Cholerae toxin (CT) extraction}

$V$. cholerae (VC1) colonies were inoculated in LB broth (Lennox) with and without the presence of $100 \mu \mathrm{M}$ tryptophol acetate and incubated for $16 \mathrm{~h}$ at $30^{\circ} \mathrm{C}$. Culture supernatants were obtained by centrifugation of these cultures at $1100 \mathrm{xg}$ for $10 \mathrm{~min}$. The cell pellets were washed with PBS and subjected to sonication for $6 \mathrm{~min}$ (30 s on and $30 \mathrm{~s}$ off) in ice. After sonication, the cell lysates were centrifuged at $1100 \mathrm{xg}$ for $5 \mathrm{~min}$ at $4{ }^{\circ} \mathrm{C}$, filter sterilized using $0.22 \mu \mathrm{m}$ filter unit (94427, Tracer) and saved in sterile vials.

\section{Cytotoxicity assay}

HeLa cells were grown in 24-well plates (10769-220, VWR International) DMEM supplemented with $10 \%$ fetal bovine serum (FBS), 2 mM glutamine (03-020-1; Biological industries), $1 \times$ PSN antibiotic mixture (03031-1; Biological industries) at $37{ }^{\circ} \mathrm{C}$ in humidified $5 \%$ $\mathrm{CO}_{2}$ incubator for $24 \mathrm{~h}$. Subsequently, the medium was replaced with fresh medium combined with $50 \mu \mathrm{L}$ extracted cholerae toxin (CT) (CT extractions from $V$. cholerae (VC1) were grown in the presence and absence of tryptophol acetate) indicated above and incubated for 16 h. After incubation, the dead cells were stained with Propidium iodide and viable cells were stained green with Syto 9 (BacLight ${ }^{\odot}$ Dead/Live Kit, Invitrogen, Eugene, OR, USA) and the cytotoxic effects of these bacterial extracts on HeLa cells were examine using an CLSM (Plan-Apochromat $10 \times / 0.8$ M27, Zeiss LSM880, Germany). Excitations were at $488 \mathrm{~nm}$ and $561 \mathrm{~nm}$; emission 490-588 $\mathrm{nm}$ and 604-735 $\mathrm{nm}$, respectively.

\section{Immunostaining}

HeLa cells were grown on sterile coverslips in 24-well plates using DMEM supplemented with $10 \%$ fetal bovine serum and $1 \times$ PSN antibiotic mixture at $37{ }^{\circ} \mathrm{C}$ in humidified $5 \%$ $\mathrm{CO}_{2}$ incubator for $24 \mathrm{~h}$. Subsequently, the medium was replaced with fresh medium combined with $50 \mu \mathrm{L}$ cell lysates 
either with or without presence of $100 \mu \mathrm{M}$ tryptophol acetate and incubate for $2 \mathrm{~h}$. After $2 \mathrm{~h}$ the cells were fixed using 4\% formaldehyde solution (1317681, Bio-Lab) for $10 \mathrm{~min}$, and washed with PBS and blocked with 10\% FBS (in PBS) for 15 min. All cells were stained with mouse monoclonal anticholerae toxin subunit B antibodies (1:500, 200844, SigmaAldrich). Cells were then subjected to a secondary antibody staining using goat anti-mouse secondary antibodies Allophycocyanin-conjugated (1159136-068; Jackson ImmunoResearch, West Grove, PA). Finally, cells were mounted with BacLight ${ }^{\mathrm{Tw}}$ mounting oil (Invitrogen, Eugene, OR, USA). Cells were imaged using CLSM (Plan-Apochromat 20×/0.8 M27, Zeiss LSM880, Germany).

\section{Statistical analyses}

All results are expressed as mean $\pm \mathrm{SD}$ as indicated. Statistical analyses were done using OriginLab software. Comparisons between three or more groups were performed using one-way ANOVA followed by Tukey's post hoc test as indicated. A $p$ value of $\leq 0.05$ was considered to be statistically significant.

\section{Supplementary Information}

The online version contains supplementary material available at https://doi. org/10.1186/s40168-021-01027-8.

Additional file 1: Table S1. Identification of microorganisms in kefir based on a BLAST comparison in the One Codex data platform for applied microbial genomics. Table S2. Distribution counts of the microorganism population as analyzed by Imagestream ${ }^{\circledast}$ flow cytometry.

Figure S1. The effect of tryptophol acetate on bacterial growth. a Vibrio harveyi b Agrobacterium tumefaciens c Vibrio cholerae. Growth curves were recorded without and with tryptophol acetate extracted from the kefir mixture. d Vibrio cholerae grown in the presence of synthesized tryptophol acetate $(200 \mu \mathrm{M})$. Figure S2. Effect of tryptophol acetate (in concentration of $200 \mu \mathrm{M}$ ) on Pseudomonas aeruginosa bacterial growth. Figure S3. Characterization of tryptophol acetate. (A) GC-MS chromatogram of the molecule showing the retention time spectra and (B) the characteristic $\mathrm{m} / \mathrm{z}$ spectra showing the fragmentation mass of $144.1 \mathrm{kDa}$. (C) ${ }^{1} \mathrm{H}$ NMR spectrum: $\delta 2.05(3 \mathrm{H}, \mathrm{s}), 3.08(2 \mathrm{H}, \mathrm{t}, \mathrm{J}=5.2 \mathrm{~Hz}), 4.40(2 \mathrm{H}, \mathrm{t}, \mathrm{J}=$ $5.2 \mathrm{~Hz}), 6.93-7.12(2 \mathrm{H}, 6.98(\mathrm{ddd}, J=8.0,7.8,1.2 \mathrm{~Hz}), 7.07(\mathrm{ddd}, \mathrm{J}=8.0,7.8$, $1.6 \mathrm{~Hz})), 7.30-7.36(2 \mathrm{H}, 7.33(\mathrm{dddd}, \mathrm{J}=8.0,1.2,0.5,0.5 \mathrm{~Hz}), 7.32(\mathrm{t}, \mathrm{J}=0.5$ $\mathrm{Hz})$ ), $7.62(1 \mathrm{H}, \mathrm{dddd}, \mathrm{J}=8.0,1.6,0.5,0.5 \mathrm{~Hz}) .(\mathrm{D}){ }^{13} \mathrm{C}$ NMR spectrum: (100 $\left.\mathrm{MHz}_{1} \mathrm{CDCl}_{3}\right) \delta 171.6,136.4,127.5,122.37,122.1,119.5,118.8,111.8,111.4$, $64.9,24.9,21.2$. Figure S4. Schemes depicting $V$. cholerae quorum sensing regulation of virulence and biofilm formation in high and low cell densities, respectively.

\section{Acknowledgements}

O.M. is grateful for a PhD Fellowship from the Strauss Group Institute. We thank Prof. Elena Voronov for providing us the Hoechst stain solution and Prof. Angel Porgador for providing us the goat anti-mouse Allophycocyaninconjugated antibody. Special thanks to Prof. Ron N. Apte for commenting on the manuscript.

\section{Authors' contributions}

Conceptualization, O.M. and R.J.; methodology and experimental design, O.M., R.S., O.B.D., A.K, M.M., and R.J.; experiments and data analysis, O.M., D.K., K.Y., R.S., M.R, and O.B.D.; writing-original draft, O.M. and R.J.; writing —review and editing, A.K., M.M., and R.J.; All authors read and approved the final manuscript.
Funding

The authors received no specific funding for this work.

\section{Availability of data and materials}

The main data supporting the findings of this study are available within the article and in its Supplementary Information. All other data supporting the findings of this study are available from the corresponding authors upon request.

Ethics approval and consent to participate

Not applicable.

Consent for publication

Not applicable.

\section{Competing interests}

The authors declare that they have no competing interests.

\section{Author details}

'Department of Chemistry, Ben-Gurion University of the Negev, 84105 Be'er Sheva, Israel. ${ }^{2}$ Avram and Stella Goldstein-Goren Department of

Biotechnology Engineering, Ben-Gurion University of the Negev, 84105 Be'er Sheva, Israel. ${ }^{3}$ National Institute for Biotechnology in the Negev, Ben-Gurion University of the Negev, 84105 Be'er Sheva, Israel. ${ }^{4}$ Ilse Katz Institute for Nanoscale Science \& Technology, Ben Gurion University of the Negev, 84105 Be'er Sheva, Israel.

Received: 15 December 2020 Accepted: 5 February 2021

Published online: 24 March 2021

\section{References}

1. Santos A, San Mauro M, Sanchez A, Torres JM, Marquina D. The antimicrobial properties of different strains of Lactobacillus spp. isolated from kefir. Syst Appl Microbiol. 2003;26(3):434-7. https://doi.org/10.1078/ 072320203322497464

2. Bourrie $B C$, Willing BP, Cotter PD. The microbiota and health promoting characteristics of the fermented beverage kefir. Front Microbiol. 2016;7:647.

3. Franco MC, Golowczyc MA, De Antoni GL, Pe PF. Administration of kefirfermented milk protects mice against Giardia intestinalis infection printed in Great Britain. J Med Microbiol. 2013;62(12):1815-22. https://doi.org/10.1099/ jmm.0.068064-0.

4. Rosa DD, Dias MM, Grzeskowiak LM, Reis SA, Conceicao LL, Peluzio MD. Milk, kefir: nutritional, microbiological and health benefits. Nutr Res Rev. 2017:30:1-15

5. Gibbs KA, Federle MJ. A social medium: ASM's 5th cell-cell communication in bacteria meeting in review. J Bacteriol. 2015;197(13):2084-91. https://doi. org/10.1128/JB.00161-15.

6. Waters CM, Bassler BL. Quorum sensing: cell-to-cell communication in bacteria. Annu Rev Cell Dev Biol. 2005;21(1):319-46. https://doi.org/10.114 6/annurev.cellbio.21.012704.131001.

7. LaSarre B, Federle MJ. Exploiting quorum sensing to confuse bacterial pathogens. Microbiol Mol Biol Rev. 2013;77(1):73-111. https://doi.org/10.112 8/MMBR.00046-12.

8. Castillo-Juárez I, Maeda T, Mandujano-Tinoco EA, Tomás M, Pérez-Eretza B, García-Contreras SJ, Wood TK, García-Contreras R. Role of quorum sensing in bacterial infections. World J Clin Cases. 2015;3(7):575-98. https://doi.org/1 0.12998/wjcc.v3.i7.575.

9. Natrah FM, Defoirdt T, Sorgeloos P, Bossier P. Disruption of bacterial cell-to-cell communication by marine organisms and its relevance to aquaculture. Mar Biotechnol. 2011;13(2):109-26. https://doi.org/10.1007/s10126-010-9346-3.

10. Khan F, Oloketuyi SF, Kim YM. Diversity of bacteria and bacterial products as antibiofilm and antiquorum sensing drugs against pathogenic bacteria. Curr Drug Targets. 2019;20(11):1156-79. https://doi.org/10.2174/13894501206661 90423161249

11. Wu H, Song Z, Hentzer M, Andersen JB, Molin N, Givskov M, Høiby S. Synthetic furanones inhibit quorum-sensing and enhance bacterial clearance in Pseudomonas aeruginosa lung infection in mice. J Antimicrob Chemother. 2004;53(6):1054-61. https://doi.org/10.1093/jac/dkh223.

12. Rajalaxmi M, Beema Shafreen R, Chithiraiselvi K, Karutha Pandian S. An in vitro and in silico identification of antibiofilm small molecules from 
seawater metaclone SWMC166 against Vibrio cholerae O1. Mol Cell Probes. 2018;39:14-24. https://doi.org/10.1016/j.mcp.2018.03.003.

13. Mellbye B, Schuster $M$. The sociomicrobiology of antivirulence drug resistance: a proof of concept. MBio. 2011;2:e00131-11.

14. Piewngam $P$, Zheng $Y$, Nguyen TH, Dickey SW, Joo HS, Villaruz AE, Glose MF, Emilie L, Hunt RL, Li B, Chiou J, Pharkjaksu S, Khongthong S, Cheung GYC, Kiratisin P, Otto M. Pathogen elimination by probiotic Bacillus via signalling interference. Nature. 2018;562(7728):532-7. https://doi.org/10.103 8/s41586-018-0616-y

15. Laćan G, Magnus V, Jericevic B, Kunst L, Iskric S. Formation of tryptophol galactoside and an unknown tryptophol ester in Euglena gracilis. Plant Physiol. 1984;76(4):889-93. https://doi.org/10.1104/pp.76.4.889.

16. Laćan G, Magnus V, Simaga S, Iskric S, Hall PJ. Metabolism of tryptophol in higher and lower plants. Plant Physiol. 1985;78(3):447-54. https://doi.org/1 0.1104/pp.78.3.447.

17. Miller MB, Skorupski K, Lenz DH, Taylor RK, Bassler BL. Parallel quorum sensing systems converge to regulate virulence in Vibrio cholerae. Cell. 2002;110(3):303-14. https://doi.org/10.1016/50092-8674(02)00829-2.

18. Bassler BL, Greenberg EP, Stevens ANNM. Cross-species induction of luminescence in the quorum- sensing bacterium Vibrio harveyi. J Bacteriol. 1997:179(12):4043-5. https://doi.org/10.1128/JB.179.12.4043-4045.1997.

19. Zhu J, Chai Y, Zhong Z, Li S, Winans SC. Agrobacterium bioassay strain for ultrasensitive detection of N -Acylhomoserine Lactone-Type QuorumSensing Molecules : Detection of Autoinducers in Mesorhizobium huakuii. Appl Environ Microbiol. 2003;69(11):6949-53. https://doi.org/10.1128/AEM. 69.11.6949-6953.2003.

20. Henke JM, Bassler BL. Three parallel quorum-sensing systems regulate gene expression in Vibrio harveyi. J Bacteriol. 2004;186(20):6902-14. https://doi. org/10.1128/JB.186.20.6902-6914.2004

21. Nackerdien ZE, Keynan A, Bassler BL, Lederberg J, Thaler DS. Quorum sensing influences vibrio harveyi growth rates in a manner not fully accounted for by the marker effect of bioluminescence. PLoS ONE. 2008; 3(2):e1671. https://doi.org/10.1371/journal.pone.0001671.

22. Bernier SP, Beeston AL, Sokol PA. Detection of $\mathrm{N}$-acyl homoserine lactones using a tral-luXCDABE-based biosensor as a high-throughput screening tool. BMC Biotechnol. 2008:8:4-8.

23. Limoli DH, Jones CJ, Wozniak DJ, Cruz S. Bacterial extracellular polysaccharides in biofilm formation and function. Microbiol Spectr. 2015;3:1-30.

24. Parsek MR, Greenberg EP. Sociomicrobiology: the connections between quorum sensing and biofilms. Trends Microbiol. 2005;13(1):27-33. https:// doi.org/10.1016/j.tim.2004.11.007.

25. von Eckardstein L, Petras D, Dang T, Cociancich S, Sabri S, Grätz S, Kerwat D, Seidel M, Pesic A, Dorrestein PC, Royer M, Weston JB, Süssmuth RD. Total synthesis and biological assessment of novel albicidins discovered by mass spectrometric networking. Chem Eur J. 2017;23(61):15316-21. https://doi. org/10.1002/chem.201704074.

26. Padder SA, Prasad R, Shah AH. Quorum sensing: a less known mode of communication among fungi. Microbiol Res. 2018;210:51-8. https://doi. org/10.1016/j.micres.2018.03.007.

27. Colwell RR. Global climate and infectious disease : the cholera paradigm. Science. 1996;274(5295):2025-31. https://doi.org/10.1126/science.274.5295.2025.

28. Kelly RC, Bolitho ME, Higgins DA, Lu W, Ng W, Jeffrey PD, Rabinowitz JD, Semmelhack MF, Hughson FM, Bassler BL. The Vibrio cholerae quorumsensing autoinducer CAl-1 : analysis of the biosynthetic enzyme CqsA. Nat Chem Biol. 2009:5:1-5.

29. Hammer BK, Bassler BL. Quorum sensing controls biofilm formation in Vibrio cholerae. Mol Microbiol. 2003;50(1):101-14. https://doi.org/10.1046/j.1365-2 958.2003.03688.x.

30. Shukla SK, Rao TS. An improved crystal violet assay for biofilm quantification in 96-well microtitre plate. Biorexiv. 2017:1-10.

31. Boyaci H, Shah T, Hurley A, Kokona B, Li Z, Ventocilla C, Jeffrey PD, Semmelhack MF, Fairman R, Bassler BL, Hughson FM. Structure, regulation, and inhibition of the quorum-sensing signal integrator LuXO. PLOS Biol. 2016;14(5):e1002464. https://doi.org/10.1371/journal.pbio.1002464.

32. Jobling MG, Holmes RK. Characterization of hapR, a positive regulator of the Vibrio cholerae HA / protease gene hap, and its identification as a functional homologue of the Vibrio harveyi luxR gene. Mol Microbiol. 1997; 26(5):1023-34. https://doi.org/10.1046/j.1365-2958.1997.6402011.x.

33. Zhu J, Miller MB, Vance RE, Dziejman M, Bassler BL, Mekalanos JJ. Quorumsensing regulators control virulence gene expression in Vibrio cholerae. PNAS. 2002;99(5):3129-34. https://doi.org/10.1073/pnas.052694299.
34. Zhu J, Mekalanos JJ. Quorum sensing-dependent biofilms enhance colonization in Vibrio cholerae. Dev Cell. 2003;5(4):647-56. https://doi.org/1 0.1016/S1534-5807(03)00295-8.

35. Schauder S, Shokat KM, Surette G, Bassler BL. The LuxS family of bacterial autoinducers: Biosynthesis of a novel quorum-sensing signal molecule. Mol Microbiol. 2001;41 (2):463-76. https://doi.org/10.1046/j.1365-2958.2001.02532.x.

36. Wu Z, Milton D, Nybom P, Sjo A. Vibrio cholerae hemagglutinin/protease (HA/ protease) causes morphological changes in cultured epithelial cells and perturbs their paracellular barrier function. Microb Pathog. 1996;21(2): 111-23. https://doi.org/10.1006/mpat.1996.0047.

37. Higgins DA, Pomianek ME, Kraml CM, Taylor RK, Semmelhack MF, Bassler BL. The major Vibrio cholerae autoinducer and its role in virulence factor production. Nature. 2007;450(7171):883-6. https:/doi.org/10.1038/nature06284.

38. Suva A, Fando R, Benitez JA. Overexpression of a mutant B subunit in toxigenic Vibrio cholerae diminishes production of active cholera toxin in vivo. Curr Microbiol. 1998;37:231-5.

39. Sokol PA, Sajjan U, Visser MB, Gingues S, Forstner J, Kooi C. The CepIR quorum-sensing system contributes to the virulence of Burkholderia cenocepacia respiratory infections. Microbiology. 2003;149(12):3649-58. https://doi.org/10.1099/mic.0.26540-0.

40. Surette MG, Miller MB, Bassler BL. Quorum sensing in Escherichia coli, Salmonella typhimurium, and Vibrio harveyi: a new family of genes responsible for autoinducer production. Proc Natl Acad Sci. 1999;96(4):163944. https://doi.org/10.1073/pnas.96.4.1639.

41. Yerushalmi SM, Buck ME, Lynn DM, Lemcoff NG, Meijler MM. Multivalent alteration of quorum sensing in Staphylococcus aureus. Chem Commun. 2013;49(45):5177-9. https://doi.org/10.1039/c3cc41645c.

42. Lee SH, Jung BY, Rayamahji N, Lee HS, Jeon WJ, Choi KS, Kweon CH, Yoo HS. A multiplex real-time PCR for differential detection and quantification of Salmonella spp., Salmonella enterica serovar Typhimurium and Enteritidis in meats. J Vet Sci. 2009;10(1):43-51. https://doi.org/10.4142/jvs.2009.10.1.43.

43. Dominical V, Samsel L, McCoy JP Jr. Masks in imaging flow cytometry. Methods. 2017;112:9-17. https://doi.org/10.1016/j.ymeth.2016.07.013.

44. Shao C, Shi G, Zhang Y, Pan S, Guanb X. Palladium-catalyzed C-H ethoxycarbonyldifluoromethylation of electron-rich heteroarenes. Org Lett. 2015;17(11):2652-5. https://doi.org/10.1021/acs.orglett.5b01024.

\section{Publisher's Note}

Springer Nature remains neutral with regard to jurisdictional claims in published maps and institutional affiliations.

Ready to submit your research? Choose BMC and benefit from

- fast, convenient online submission

- thorough peer review by experienced researchers in your field

- rapid publication on acceptance

- support for research data, including large and complex data types

- gold Open Access which fosters wider collaboration and increased citations

- maximum visibility for your research: over $100 \mathrm{M}$ website views per year

At BMC, research is always in progress.

Learn more biomedcentral.com/submissions 